\title{
MODAL AND HARMONIC ANALYSIS OF A CANTILVER BEAM
}

\section{WITH DIFFERRENT CROSS-SECTIONS}

\author{
SUDHAKARA REDDY KALAVAPALLI ${ }^{1}$, T. N. RAVI KANTH ${ }^{2} \&$ K RAJA SEKHAR REDDY ${ }^{3}$ \\ ${ }^{1,2}$ Associate Professor, Department of Mechanical Engineering, MLR institute of technology (UGC AUTONOMOUS), \\ Dundigal, Hyderabad, Telangana, India \\ ${ }^{3}$ Assistant Professor, Department of Mechanical Engineering, Vardhaman College of Engineering,
}

Shamshabad, Hyderabad, Telangana, India

Modal analysis helps to determine the system frequencies and to obtain the eigen modes of various structural members subjected to vibration. In this research, modal analysis and harmonic analysis of a cantilever beam with different sections of same weight and material i.e., rectangle, T-section and I-section are carried out using ANSYS software, to see the mode shapes and to observe the dynamic response of the cantilever beam, and to identify the best configuration of the beam.
\end{abstract}

KEYWORDS: Modal Analysis, Mode Shapes, Natural Frequencies, Harmonic Analysis, Dynamic Response \& Ansys

Received: Nov 18, 2017; Accepted: Dec 08, 2017; Published: Jan 05, 2018; Paper Id.: IJMPERDFEB201837

\section{INTRODUCTION}

It is very important to control the resonance in any structure which is subjected to dynamic loads, as it leads to failure. Modal analysis helps the designer to determine the system frequencies and eigen modes, which inturn gives idea how the structure will respond to various dynamic loads. Based on the type of response, the response analysis is carried to find the amplitude. In many bridge constructions, some parts are made as cantilever, which is subjected to sinusoidal vibrations. Hence, in this project, it is aimed to study the dynamic response of a cantilever beam under differrent configurations to certify the best one by harmonic analysis using ANSYS.

\section{MATERIAL PROPERTIES}

Young's Modulus $=2 \times 10^{5} \mathrm{~N} / \mathrm{mm}^{2}$

Density of the material $=7.7 \times 10^{-6} \mathrm{~kg} / \mathrm{mm}^{3}$

Poisson's Ratio $=0.3$

\section{MODAL ANALYSIS OF CANTILEVER BEAM WITH RECTANGULAR SECTION USING ANSYS}

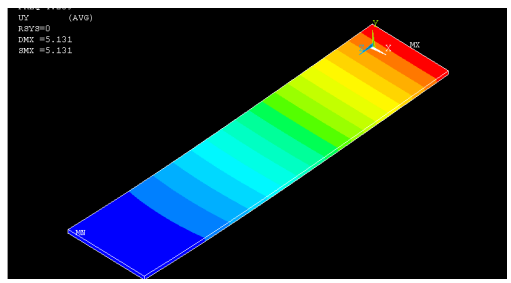

(a) Eigen Mode 1

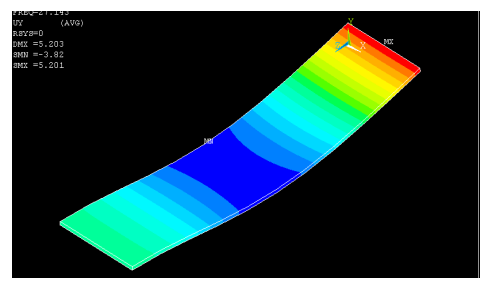

(b) Eigen Mode 2 


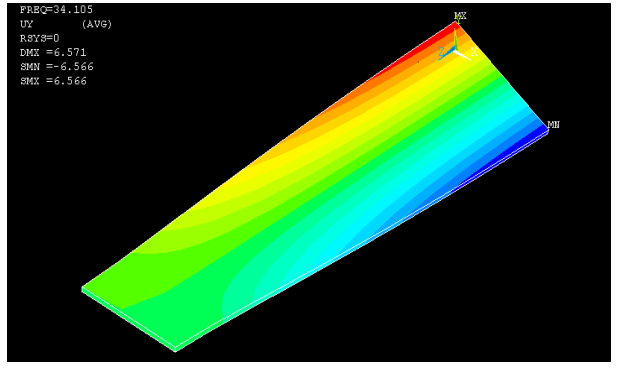

(c) Eigen Mode 3

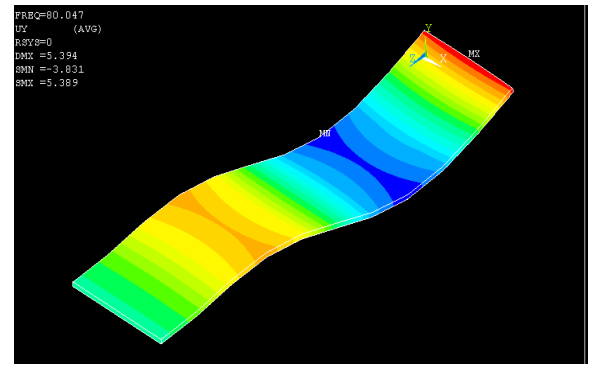

(d) Eigen Mode 4

Figure 1: Eigen Modes of a Cantilever of Beam with Rectangular Section

\section{MODAL ANALYSIS OF CANTILEVER BEAM WITH RECTANGULAR T-SECTION USING ANSYS}

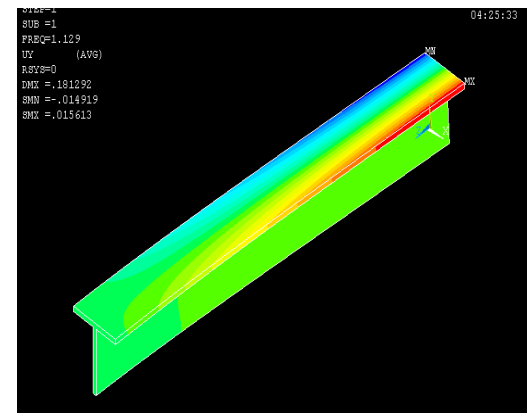

(a) Eigen Mode 1

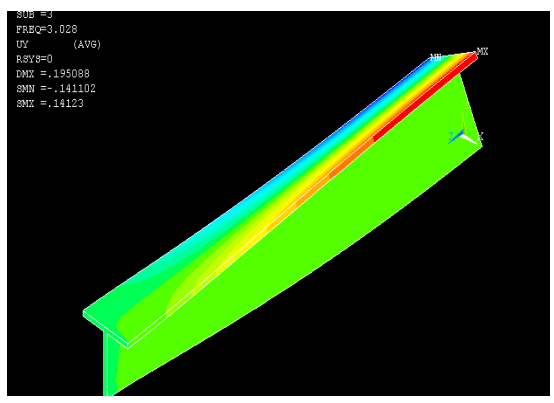

(c) Eigen Mode 3

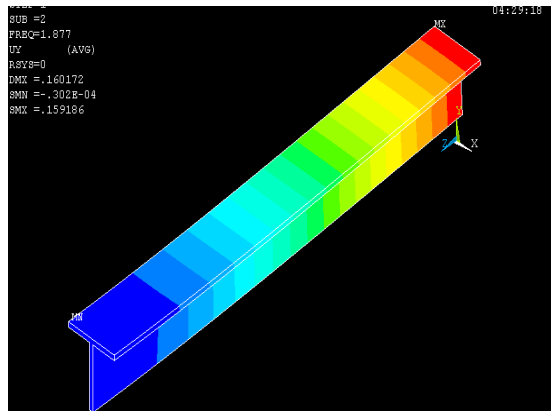

(b) Eigen Mode 2

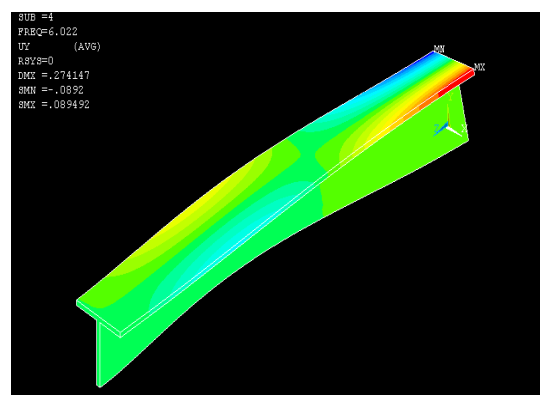

(d) Eigen Mode 4

Figure 2: Eigen Modes of a Cantilever of Beam with T-Section

MODAL ANALYSIS OF CANTILEVER BEAM WITH I-SECTION USING ANSYS

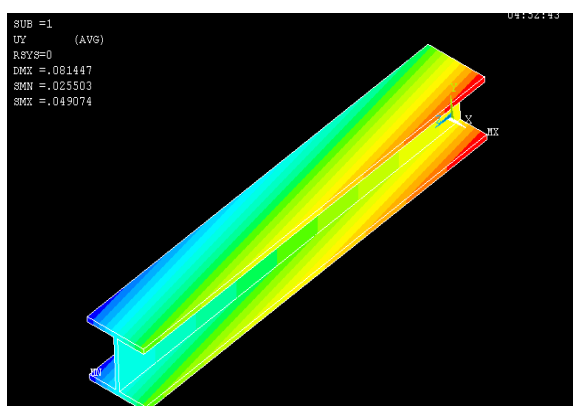

(a) Eigen Mode-1

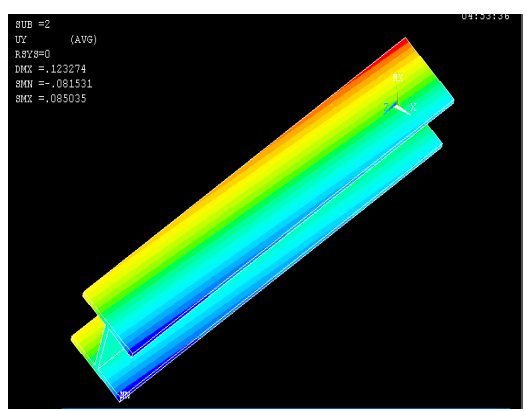

(b) Eigen Mode 2 


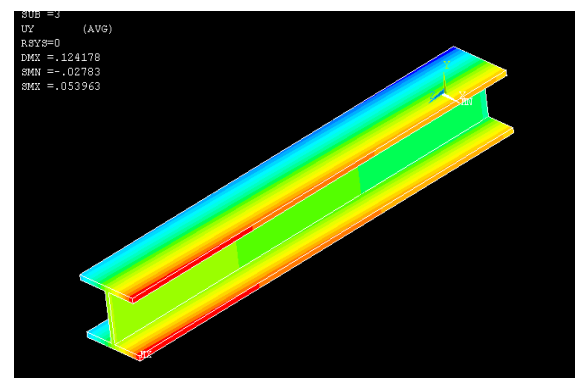

(c) Eigen Mode 3

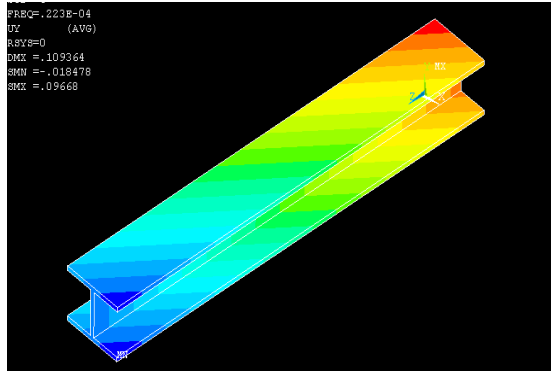

(d) Eigen Mode 4

Figure 3: Mode Shapes of a Cantilever of Beam with I-Section

\section{HARMONIC ANALYSIS OF CANTILEVER BEAM WITH RECTANGULAR SECTION USING ANSYS}

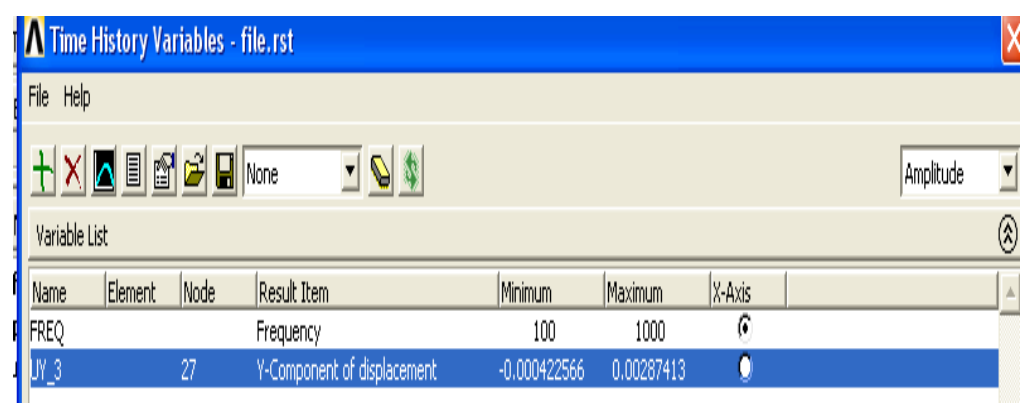

Figure 4: Amplitude of Cantilever Beam of Rectangular Section

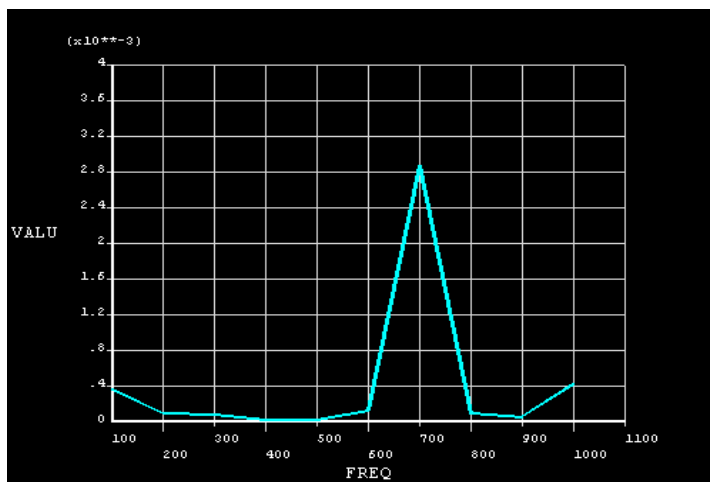

Graph 1: Frequency Vs Amplitude of Cantilever Beam of Rectangular Section

\section{HARMONIC ANALYSIS OF CANTILEVER BEAM WITH 'T' SECTION USING ANSYS}

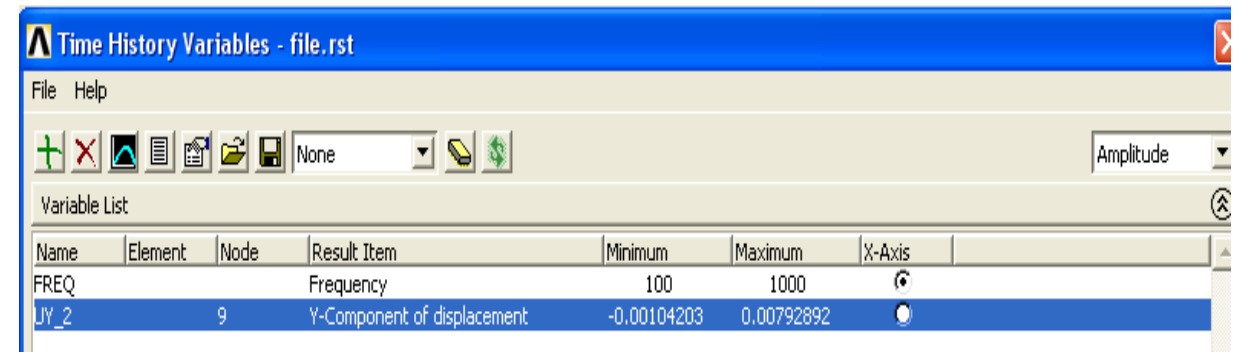

Figure 5: Amplitude of Cantilever Beam of T-Section 


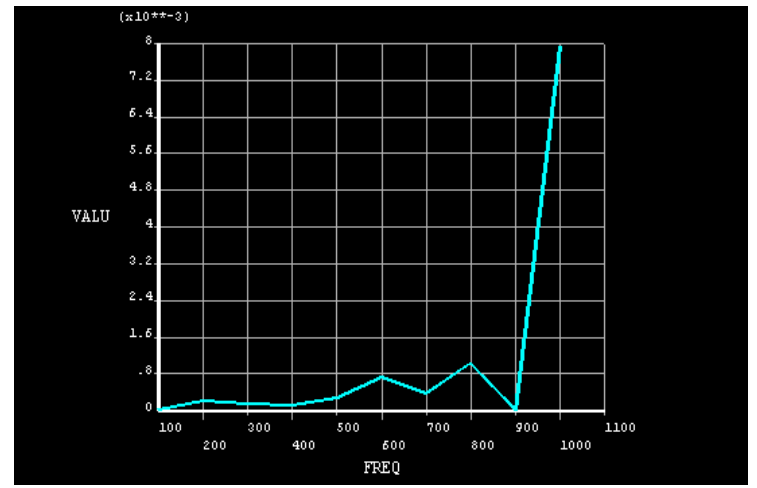

Graph 2: Frequency Vs Amplitude of Cantilever Beam of ' $T$ ' Section

\section{HARMONIC ANALYSIS OF CANTILEVER BEAM WITH 'I' SECTION USING ANSYS}

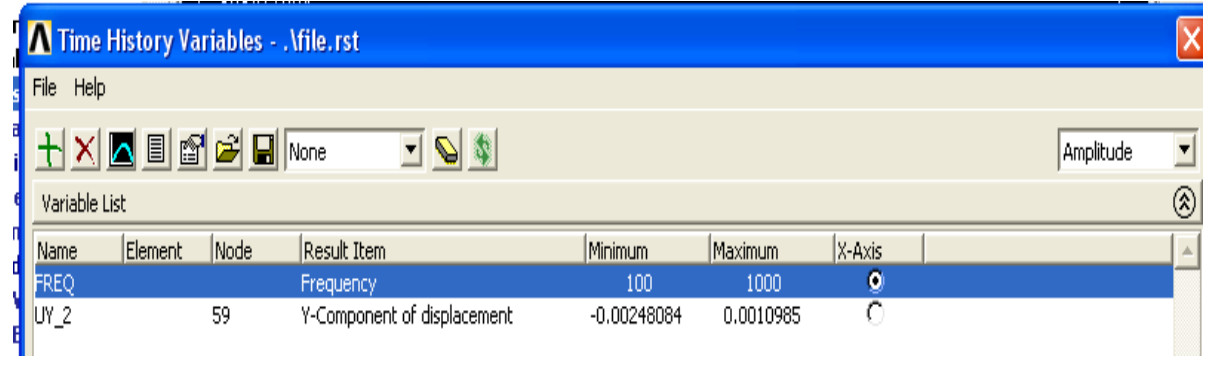

Figure 6: Amplitude of Cantilever Beam of 'I' Section

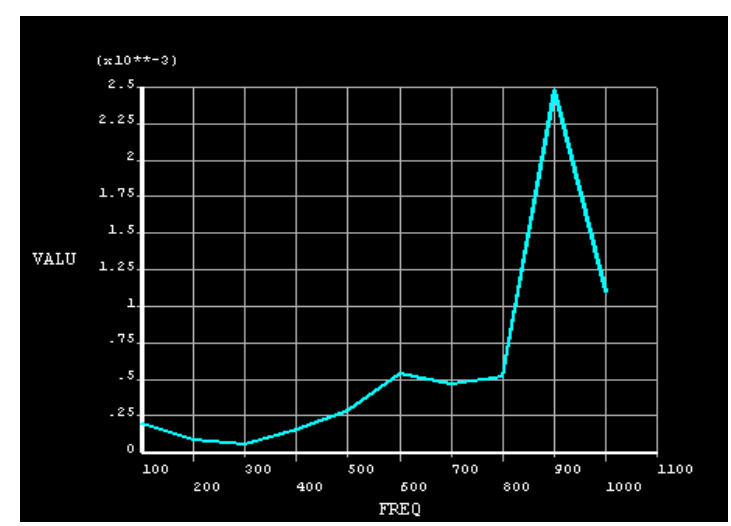

Graph 3: Frequency Vs Amplitude of Cantilever Beam of 'I' Section

\section{RESULTS \& DISCUSSIONS}

The mode shapes are illustrated above and the following results were obtained in harmonic analysis of the cantilever beam, with different transverse sections.

\begin{tabular}{|c|l|c|}
\hline S. No & Type of Section & Response (Amplitude) in $\mathbf{~ m m}$ \\
\hline 1. & Rectangular & 0.0028741 \\
\hline 2. & T-Section & 0.0079289 \\
\hline 3. & I-Section & 0.0024808 \\
\hline
\end{tabular}

From the table, it is clearly observed that the cantilever beam with I-Cross section has less amplitude when compared to rectangular and T-cross sections, and hence, it is the best configuration. 


\section{CONCLUSIONS}

- The Modal analysis of a cantilever beam with different cross sections was carried and mode shapes were obtained.

- The maximum amplitude of cantilever beam with rectangular section is $0.0028741 \mathrm{~mm}$.

- The maximum amplitude of cantilever beam with T-Section is $0.0079289 \mathrm{~mm}$.

- The maximum amplitude of cantilever beam with I-Section is $0.0024808 \mathrm{~mm}$.

- The cantilever beam with I-section is the best configuration when compared to rectangular and T-sections.

\section{REFERENCES}

1. A First Course In Finite Elements (Wiley, 2007) by Fish J., Belytschko T

2. $\quad$ The Finite Element Method in Engineering - S.S. Rao

3. Qasim Bader, Effect of V Shape Notch Location on Fatigue Life in Steel Beam Made of Carbon Steel Alloys with Different Content of Carbon, International Journal of Mechanical and Production Engineering Research and Development (IJMPERD), Volume 4, Issue 4, July - August 2014, pp. 69-78

4. Introduction to Finite Elements in Engineering, Third Edition by Tirupathi R. Chandrupatla and Ashok D.Belegundu. 
